\title{
Efektifitas Bank Sampah dalam Pengelolaan Sampah di Kota Jambi
}

\author{
${ }^{1}$ David Evianto Tampubolon, ${ }^{2}$ Marhadi, ${ }^{3}$ Anggrika Riyanti \\ ${ }^{1}$ Program Studi Tenik, Universitas Batanghari, Jambi \\ ${ }^{2,3}$ Dosen Program Studi Teknik Lingkungan, Universitas Batanghari, Jambi \\ Email :
}

\begin{abstract}
Abstrak. Penelitian ini dilaksanakan di tiga Bank Sampah di Kota Jambi yang terdapat sistem 3R yaitu Reduce, Reuse, Recycle. Pengumpulan data ini didapat dari hasil survey, kuesioner, wawancara lalu di bandingkan dari 3 Bank Sampah 3R tersebut dan di dapat hasil efektifitas Bank Sampah berbasis 3R yang berada di Kota Jambi. Hasil penelitian yang penulis dapatkan adalah merupakan suatu gambaran pengetahuan yang baik, sikap yang cukup baik dan perilaku yang kurang dari masyarakat Kota Jambi terhadap sampah. Dari penelitian yang dilakukan oleh penulis, maka dapat diambil kesimpulan bahwa masyarakat Kota Jambi memiliki pengetahuan yang baik tentang sampah, sikap yang cukup baik terhadap sampah, tetapi perilaku yang kurang baik terhadap sampah dikarenakan kurang perhatian dari pemerintah.
\end{abstract}

Kata kunci : Bank sampah; tpst; efektivitas

\section{PENDAHULUAN}

Sampah merupakan hasil dari adanya aktivitas manusia dan juga berasal dari alam. Seiring peningkatan populasi penduduk dan pertumbuhan ekonomi, pengelolaan sampah sebagian besar kota hingga saat ini masih menimbulkan permasalahan yang sulit dikendalikan. Pengelolaan sampah yang dilakukan oleh masyarakat hanya melalui pengumpulan sampah di rumah masing-masing dan ataupun langsung dibawa ke Tempat Penampungan Sementara (TPS). Sampah di Tempat Penampungan Sementara (TPS) kemudian diangkut oleh mobil sampah kemudian dibuang ke Tempat Pembuangan Akhir (TPA).

Undang-undang Nomor 18 Tahun 2008 Tentang Pengelolaan Sampah dan perlunya perubahan pola pengelolaan sampah konvensional menjadi pengelolaan sampah yang bertumpu pada pengurangan dan penanganan sampah. Peraturan Menteri Lingkungan Hidup Nomor 13 Tahun 2012 Tentang Pedoman Pelaksanaan Reduce, Reuse, Recycle Melalui Bank Sampah menjelaskan bahwa Pengurangan sampah dapat dilakukan dengan kegiatan membatasi timbulan sampah, mendaur ulang dan memanfaatkan kembali sampah atau dikenal dengan 3R (reduce, reuse, dan recycle). Salah satu penerapan 3R yang dapat dilakukan adalah melalui Bank Sampah dan Tempat Pengelolaan Sampah Terpadu (TPST).

\section{METODE PENELITIAN}

Dalam penelitian ini pengumpulan data yang dilakukan melalui observasi, wawancara, dan kuisioner di 3 Bank Sampah dan TPST yang ada di kota jambi yaitu Bank Sampah dan TPST Sinar Kenali dengan jumlah nasabah \pm 100 orang, Bank Sampah dan TPST Jaya Abadi dengan jumlah nasabah \pm 280 orang, Bank Sampah dan TPST Mekar Sari dengan jumlah nasabah \pm 180 orang. Data yang akan diambil adalah sebagai berikut : Data Primer Pengumpulan data primer didapat dari survey lapangan, kuisioner dan wawancara adapun Data sekunder data yang dikumpulkan dari sumber-sumber yang ada atau disebut tersedia .

\section{HASIL DAN PEMBAHASAN}

Mekanisme kerja Bank Sampah yang diterapkan di Bank Sampah 3R Mekarsari yaitu mulai dari Pemilahan, Penyetoran sampah ke Bank Sampah KSM Mekar Sari yang sampai saat ini memiliki nasabah berjumlah \pm 280 orang, Bank KSM Sinar Kenali bekerja sama dengan Pertamina Drilling Service mengembangkan Bank Sampah yang sampai saat ini terhitung bulan Mei 2018 memiliki nasabah berjumlah \pm 100 orang dan KSM Mekar Sari yang sampai saat ini memiliki nasabah berjumlah \pm 400 orang, adapun proyeksi timbulan sampah di tiap-tiap bank sampah sebagai berikut : 
Tabel 1. Proyeksi Timbulan Sampah di Bank Sampah 3R Mekar Sari

\begin{tabular}{cccc}
\hline Tahun & $\begin{array}{c}\text { Jumlah Penduduk } \\
\text { (Orang) }\end{array}$ & $\begin{array}{c}\text { Jumlah Volume Sampah Harian } \\
\text { (M3/Hari) }\end{array}$ & $\begin{array}{c}\text { Volume Sampah Terolah di Bank } \\
\text { Sampah Mekar Sari (M3/Tahun) }\end{array}$ \\
\hline $\mathbf{( 1 )}$ & $\mathbf{( 2 )}$ & $(\mathbf{3})$ & $\mathbf{( 4 )}$ \\
2015 & 576067 & 1497774 & 900 \\
2016 & 583487 & 1808809 & 1000 \\
2017 & 591134 & 2003944 & 2736502 \\
2018 & 592316 & 2144183 & 2890348 \\
2019 & 593500 & 2296845 & 3056695 \\
2020 & 594687 & 2462004 & 3229651 \\
2021 & 595876 & 2633771 & 3415227 \\
2022 & 597067 & 2818156 & 3619484 \\
2023 & 598261 & 3021218 & 3836529 \\
\hline
\end{tabular}

Sumber : Hasil perhitungan tahun 2018

Pada Tabel 1 menunjukkan proyeksi volume sampah yang terolah di Bank Sampah dan TPST Sinar Kenali pada tahun 2024 yaitu sebesar 3836529 M³/Tahun atau di rata-ratakan menjadi 2,22M3/Tahun dengan jumlah timbulan sampah di Kota Jambi pada tahun 2015 yaitu sebesar 35,64 M³/Tahun, dan didapat hasil dari pengurangan sampah di Bank Sampah dan TPST Mekar Sari sebesar 28,65 M³/Tahun. Sedangkan untuk efektifitas Bank Sampah dan TPST Mekar Sari melalui wawancara dan kuisioner efektif sebesar 90\%

Tabel 2. Proyeksi Timbulan Sampah di Bank Sampah 3R Jaya Abadi

\begin{tabular}{cccc}
\hline Tahun & $\begin{array}{c}\text { Jumlah Penduduk } \\
\text { (Orang) }\end{array}$ & $\begin{array}{c}\text { Jumlah Volume Sampah Harian } \\
(\mathbf{M} \text { /Hari) }\end{array}$ & $\begin{array}{c}\text { Volume SampahTerolah di Bank } \\
\text { Sampah Jaya Abadi (M3/Tahun) }\end{array}$ \\
\hline $\mathbf{( 1 )}$ & $\mathbf{( 2 )}$ & $\mathbf{( 3 )}$ & $\mathbf{( 4 )}$ \\
2015 & 576067 & 1497774 & 860 \\
2016 & 583487 & 1808809 & 970 \\
2017 & 591134 & 2003944 & 2736502 \\
2018 & 592316 & 2144183 & 2890348 \\
2019 & 593500 & 2296845 & 3056695 \\
2020 & 594687 & 2462004 & 3229651 \\
2021 & 595876 & 2633771 & 3415227 \\
2022 & 597067 & 2818156 & 3619484 \\
2023 & 598261 & 3021218 & 3836529 \\
2024 & 599457 & 3237067 & \\
\hline
\end{tabular}

Sumber : Hasil perhitungan tahun 2018

Pada tabel 2. menunjukkan proyeksi volume sampah yang terolah di Bank Sampah dan TPST Jaya Abadi pada tahun 2024 yaitu sebesar $3836529 \mathrm{M}^{3} /$ Tahun atau di rata-ratakan menjadi 2,21 $\mathrm{M}^{3} / \mathrm{Tahun}$ dengan jumlah timbulan sampah di Kota Jambi pada tahun 2015 yaitu sebesar 35,64 M³/Tahun, dan didapat hasil dari pengurangan sampah di Bank Sampah dan TPST Jaya Abadi sebesar 28,64M³/Tahun. Sedangkan untuk efektifitas Bank Sampah dan TPST Jaya Abadi melalui wawancara dan kuisioner efektif sebesar 88\%

Tabel 3. ProyeksiTimbulanSampah di Bank Sampah 3R Sinar Kenali

\begin{tabular}{cccc}
\hline Tahun & $\begin{array}{c}\text { Jumlah Penduduk } \\
\text { (Orang) }\end{array}$ & $\begin{array}{c}\text { Jumlah Volume Sampah Harian } \\
\text { (M3/Hari) }\end{array}$ & $\begin{array}{c}\text { Volume SampahTerolah di Bank Sampah } \\
\text { Sinar Kenali (M3/Tahun) }\end{array}$ \\
\hline $\mathbf{( 1 )}$ & $\mathbf{( 2 )}$ & $\mathbf{( 3 )}$ & $\mathbf{( 4 )}$ \\
2015 & 576067 & 1497774 & 2200 \\
2016 & 583487 & 1808809 & 3000 \\
2017 & 591134 & 2003944 & 2736502 \\
2018 & 592316 & 2144183 & 2890348 \\
2019 & 593500 & 2296845 & 3056695 \\
2020 & 594687 & 2462004 & 3229651 \\
2021 & 595876 & 2633771 & 3415227 \\
2022 & 597067 & 2818156 & 3619484 \\
2023 & 598261 & 3021218 & 3836529 \\
2024 & 599457 & 3237067 & \\
\hline
\end{tabular}

Sumber : Hasil perhitungan tahun 2018 
Pada tabel 3 menunjukkan proyeksi volume sampah yang terolah di Bank Sampah dan TPST Sinar Kenali pada tahun 2024 yaitu sebesar $3836529 \mathrm{M}^{3} /$ Tahunataudi rata-ratakan menjadi 2,56M³/Tahun dengan jumlah timbulan sampah di Kota Jambi pada tahun 2015 yaitu sebesar 35,64 M³/Tahun, dan didapat hasil dari pengurangan sampah di Bank Sampah dan TPST Sinar Kenali sebesar 33,08M³/Tahun. Sedangkan untuk efektifitas Bank Sampah dan TPST Sinar Kenali melalui wawancara dan kuisioner efektif sebesar $86 \%$

\section{Perhitungan Menentukan Tingkat Efektifitas Bank Sampah di Kota Jambi}

\section{a. Bank Sampah 3R Mekar Sari}

Hasil perhitungan jawaban kuesioner oleh responden sebagai berikut :

\section{Contoh Pertanyaan Pertama :}

1) Responden yang menjawab Setuju $=43 \times 1=3$

2) Respponden yang menjawab Tidak Setuju $=0 \times 0=0$

Total Skor $=43+0=43$

Rumus Indeks \% = Total Skor $/ \mathrm{Y}$ x 100

Maka penyelesaian :

$=$ Total Skor $/$ Y x 100

$=43 / 50 \times 100$

$=86 \%$ Kategori Sangat Efektif

\section{b. Bank Sampah 3R SinarKenali}

Hasil perhitungan jawaban kuesioner oleh responden sebagai berikut :

\section{Pertanyaan Pertama:}

1) Responden yang menjawab Setuju $=41 \mathrm{x}=41$

2) Responden yang menjawab Tidak Setuju $=0 \times 0=0$

Total Skor $=5+36+0+0+0=41$

Rumus Indeks \% = Total Skor $/$ Y x 100

Maka penyelesaian :

$=$ Total Skor $/$ Y x 100

$=41 / 50 \times 100$

$=82 \%$ Kategori Sangat Efektif

\section{c. Bank Sampah 3R Jaya Abadi}

Hasil perhitungan jawaban kuesioner oleh responden sebagai berikut :

\section{Contoh Pertanyaan Pertama :}

1) Responden yang menjawab Sangat Setuju $=42 \times 1=42$

2) Responden yang menjawab Tidak Setuju $=0 \times 0=0$

Total Skor $=10+32+0+0+0=42$

Rumus Indeks \% = Total Skor / Y x 100

Maka penyelesaian :

$=$ Total Skor $/ \mathrm{Y}$ x 100

$=42 / 50 \times 100$

$=84 \%$ Kategori Sangat Efektif

\section{SIMPULAN}

1. Efektifitas Bank Sampahdan TPST Mekar Sari efektifsebesar $90 \%$

2. Efektifitas Bank Sampah dan TPST Jaya Abadi efektif sebesar $88 \%$

3. Efektifitas Bank Sampahdan TPST Sinar Kenali efektif sebesar $86 \%$

\section{DAFTAR PUSTAKA}

Alex, S. 2012. Sukses Mengolah Sampah Organik Menjadi Pupuk Organik. Pustaka Baru Press. Yogyakarta Arikunto, S. 2002. Metodologi Penelitian Suatu Pendekatan Proposal . Jakarta: PT. Rineka Cipta.

BPS Kota Jambi Dalam Angka (2013-2017)

Damanhuri, E. 2010. Diktat Pengelolaan Sampah.Teknik Lingkungan Institut Teknologi Bandung (ITB): Bandung. 
Darma setiawan,martin. 2004,Sarana sanitasi Perkotaan. Ekamitra Engineering. Jakarta

Peraturan Menteri Lingkungan Hidup Nomor 13 Tahun 2012 Tentang Pedoman Pelaksanaan Reduce, Reuse, Recycle Melalui Bank Sampah

Peraturan Menteri No.13 Tahun 2012

Suyoto, Bagong. 2008. Rumah Tangga Peduli Lingkungan. Jakarta : Prima Media

Undang-Undang Nomor 18 Tahun 2008 Pasal 1 Ayat 1 